\title{
Characterization of adrenergic and purinergic contractile responses in rat mesenteric arteries and veins
}

\author{
Rebekah Carter and Nathan Ludwig
}

This manuscript reflects the equal contributions of two authors. The project was completed for BIOM4510 Research in Biomedical Science under the supervision of Dr. Ron Johnson, Department of Biomedical Science, Ontario Veterinary College.

\begin{abstract}
Norepinephrine (NE) and adenosine 5'-triphosphate (ATP) are neurotransmitters released from sympathetic neurons that act to alter net vascular tone in the mesentery via activation of adrenergic ( $\alpha 1$ and $\alpha 2)$ and purinergic (P2X and $\mathrm{P} 2 \mathrm{Y}$ ) receptors. This study was designed to identify adrenergic and purinergic receptors in third order mesenteric arteries and veins in male Sprague-Dawley rats. Agonists and antagonists of adrenergic and purinergic receptors were exogenously applied to vessels and contractile responses were measured using computer-assisted video microscopy. NE and ATP both caused contractions of mesenteric arteries and veins. The selective $\alpha 1$ antagonist prazosin attenuated NE-derived constriction of the vessels. The selective $\alpha 1$ agonist phenylephrine was a more efficacious constrictor of both mesenteric arteries and veins than the selective $\alpha 2$ agonist clonidine. The P2X/P2 $\mathrm{Y}_{1}$ receptor antagonist pyridoxal-phosphate-6-azophenyl-2',4-disulfonic acid (PPADS) caused a rightward shift in the ATP doseresponse curve in mesenteric arteries but not veins. These data indicate that the $\alpha 1$ adrenergic receptors are the primary adrenoreceptors mediating contraction to NE in mesenteric vessels. Additionally, these data suggest that the $\mathrm{P} 2 \mathrm{X} / \mathrm{P} 2 \mathrm{Y}_{1}$ receptors mediate substantial contractile responses to ATP in mesenteric arteries but not veins.
\end{abstract}

$\mathrm{T}$ he entire splanchnic circulation can receive up to $60 \%$ of cardiac output and contains about one third of the total blood volume. ${ }^{6}$ Mesenteric arteries and veins have significant resistance and capacitance functions in the systemic circulation respectively. In comparison to the associated veins, mesenteric arteries have a high resting basal tone mediated in part by a thicker layer of vascular smooth muscle. Constriction of the mesenteric arteries is thought to increase total peripheral resistance in the systemic circulation greatly. In contrast, mesenteric veins contain fewer layers of vascular smooth muscle cells ${ }^{16}$ and are more compliant vessels. The function of these low pressure vessels is to store significant quantities of blood that can be utilized to maintain the central venous pool of blood and cardiac output. As such, the degree of vascular tone in mesenteric vasculature plays a major role in the regulation of systemic blood pressure and overall body hemodynamics.

Net vascular tone in the mesenteric vasculature is under the influence of several key factors. These factors include locally acting and circulating hormones, intrinsic myogenic properties of the vessel, as well as neurotransmitters released from perivascular post-ganglionic sympathetic neurons. In general, the arteries and veins of the splanchnic circulation are richly innervated with sympathetic nerves that act to constrict these vessels. Maximal activation of the sympathetic constrictor nerves can produce an $80 \%$ reduction in blood flow to the splanchnic region. ${ }^{10}$
In vivo, sympathetic neurogenic influence of vascular tone is mediated by three neurotransmitters. Neuropeptide Y (NPY), norepinephrine (NE), and adenosine tri-phosphate (ATP) make up the sympathetic triad of neurotransmitters. Perivascular neurons store the three sympathetic neurotransmitters in synaptic vesicles and release these neurotransmitters from varicosities to act on postjunctional receptors on the vascular smooth muscle. The arrangement of the sympathetic neurons differs between arteries and veins. The nerve plexus for mesenteric arteries consists of a bundle of axons arranged in a mesh-like network with nerve fibres equally likely to run parallel or perpendicular to the longitudinal axis of the vessel. ${ }^{13}$ In contrast, in mesenteric veins the nerve plexus consists of single axons with a circumferential nerve fibre arrangement about the vessel. ${ }^{13}$ In both cases the sympathetic neurotransmitters released cause depolarization of the nearby vascular smooth muscle. As a whole, activation the sympathetic postjunctional receptors mediates contraction of the vascular smooth muscle and therefore constriction of the artery or vein.

In vitro, electrical field stimulation studies have found that upon stimulation of mesenteric perivascular nerves a measurable amount of NE is released. ${ }^{1}$ Once released NE can act on a variety adrenoreceptors on the vascular smooth muscle. A total of 9 vascular adrenoreceptors have been identified to date: $\alpha 1 \mathrm{~A}, \alpha 1 \mathrm{~B}, \alpha 1 \mathrm{D}, \alpha 2 \mathrm{~A} / \mathrm{D}, \alpha 2 \mathrm{~B}, \alpha 2 \mathrm{C}, \beta 1, \beta 2$, and $\beta 3 .^{21}$ Previous in vitro studies have found contractile 
A

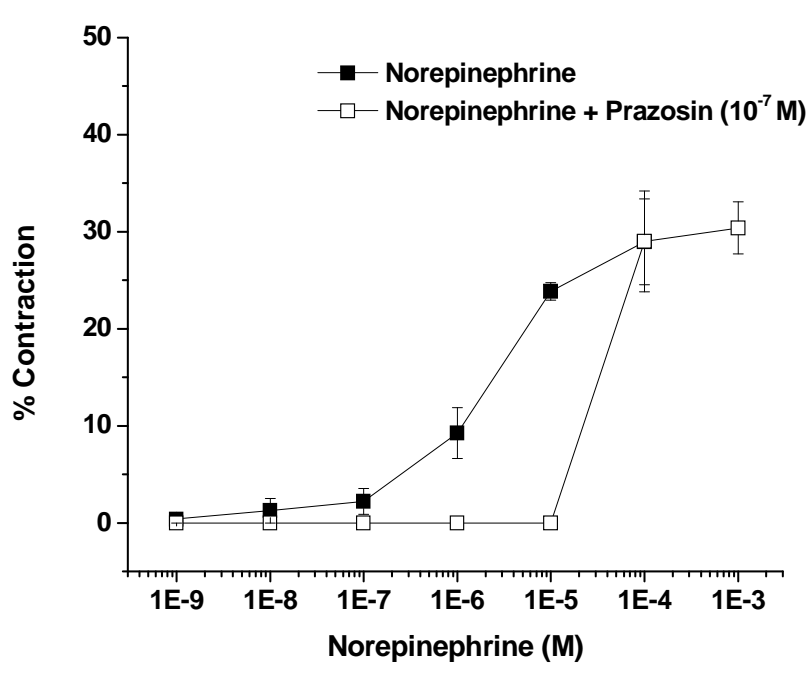

B

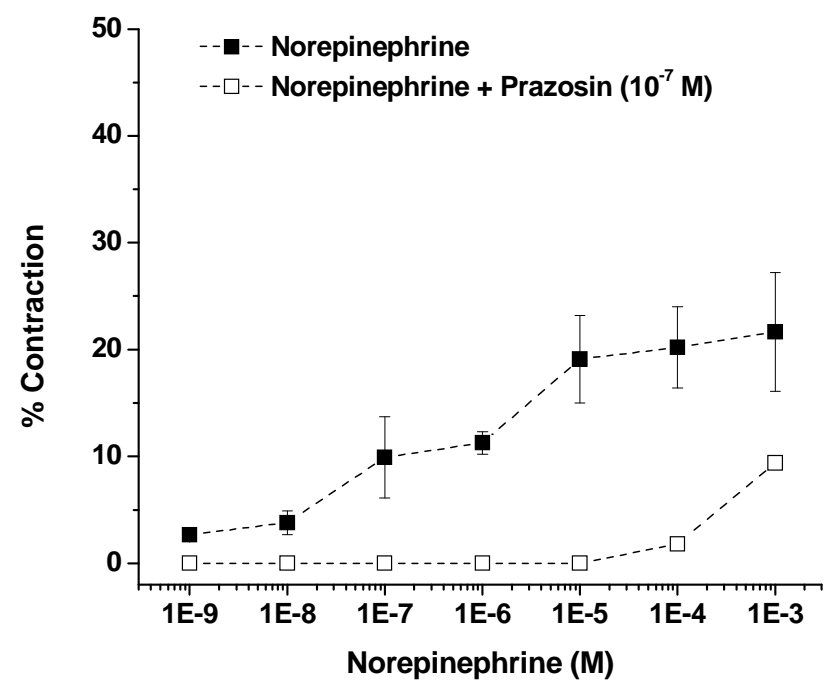

Figure 1: Dose-response curves for NE in the presence and absence of prazosin $\left(10^{-7} \mathrm{M}\right) . \mathrm{A}, \mathrm{NE}$ caused contraction of third order mesenteric arteries $(n=3)$. Prazosin decreased the NE-induced contractions $(n=2)$. B, NE caused contractions in third order mesenteric veins $(n=2)$. Prazosin decreased the NE-induced contractions $(n=1)$. Data in both figures are mean \pm SEM and $n$ indicates the number of animals from which the data were obtained.

responses to be mediated by activation of the $\alpha 1$ receptor in mesenteric arteries and both $\alpha 1$ and $\alpha 2$ receptors in mesenteric veins. ${ }^{14}$ These adrenoreceptors are G-protein linked receptors that are coupled to an intracellular increase of inositol 1,4,5-triphosphate $\left(\mathrm{IP}_{3}\right)$. Contraction of the smooth muscle is mediated by $\mathrm{IP}_{3}$ acting on sarcoplasmic reticulum receptors to release intracellular $\mathrm{Ca}^{2+}$ stores. Additional $\mathrm{Ca}^{2+}$ is taken up into the vascular smooth muscle cells following depolarization via L-type voltage-gated calcium channels.

Like NE, a measurable amount of ATP is released from perivascular sympathetic neurons when activated by electrical field stimulation. ${ }^{1}$ In vivo, ATP is thought to mediate neurogenic contractions of vascular smooth muscle by acting on various purinergic receptors present on the smooth muscle cells. The two subtypes of purinergic receptors are the $\mathrm{P} 2 \mathrm{X}$ and $\mathrm{P} 2 \mathrm{Y}$ receptors. The $\mathrm{P} 2 \mathrm{X}$ receptors are ATP-gated ion channels that cause an influx of $\mathrm{Ca}^{2+}$ into the smooth muscle cells from the extracellular environment. ${ }^{12}$ Though there are several $\mathrm{P} 2 \mathrm{X}$ receptor isoforms, there is evidence that vascular smooth muscle cells primarily express the $\mathrm{P} 2 \mathrm{X}_{1}$ receptors. ${ }^{19} \mathrm{P} 2 \mathrm{X}$ receptors are thought to be responsible for the excitatory junction potentials (rapid and short depolarization of vascular smooth muscle) present in mesenteric arteries. ${ }^{6}$ In contrast, excitatory junction potentials are not present in mesenteric veins. This is largely thought to be the result of selective expression of only the $\mathrm{P} 2 \mathrm{Y}$ receptor subtype in mesenteric veins. ${ }^{11}$ The $\mathrm{P} 2 \mathrm{Y}$ receptors mediate slower contractile responses than the $\mathrm{P} 2 \mathrm{X}$ receptors, and are G-protein linked receptors that have similar intracellular effects as the $\alpha$ adrenergic receptors. The isoforms of the $\mathrm{P} 2 \mathrm{Y}$ receptors that are thought to be expressed in vascular smooth muscle cells are the $\mathrm{P} 2 \mathrm{Y}_{2}$ and the $\mathrm{P} 2 \mathrm{Y}_{4}$ receptors. 5

Table 1: Comparison of maximal responses $\left(E_{\max }\right)$ and half-maximal effective concentrations $\left(\mathrm{EC}_{50}\right)$ for exogenous applications of adrenergic receptor agonists and antagonists in rat mesenteric arteries and veins.

\begin{tabular}{|l|c|c|c|c|}
\hline \multirow{2}{*}{ Drugs } & \multicolumn{2}{|c|}{ Arteries } & \multicolumn{2}{c|}{ Veins } \\
\cline { 2 - 5 } & $\mathbf{E C}_{\mathbf{5 0}} \mathbf{( M )}$ & $\mathbf{E}_{\mathbf{m a x}}(\boldsymbol{\%})$ & $\mathbf{E C}_{\mathbf{5 0}}(\mathbf{M})$ & $\mathbf{E m a x}(\boldsymbol{\%})$ \\
\hline $\mathrm{NE}$ & $3.2 \times 10^{-6}$ & 31.8 & $5.3 \times 10^{-7}$ & 23.7 \\
\hline NE + Prazosin & $5.0 \times 10^{-5}$ & 30.7 & $1.6 \times 10^{-4}$ & 9.4 \\
\hline Phenylephrine & $2.4 \times 10^{-6}$ & 31.8 & $2.8 \times 10^{-7}$ & 17 \\
\hline Clonidine & $1.410^{-5}$ & 10.6 & $6.6 \times 10^{-7}$ & 4.1 \\
\hline
\end{tabular}


A

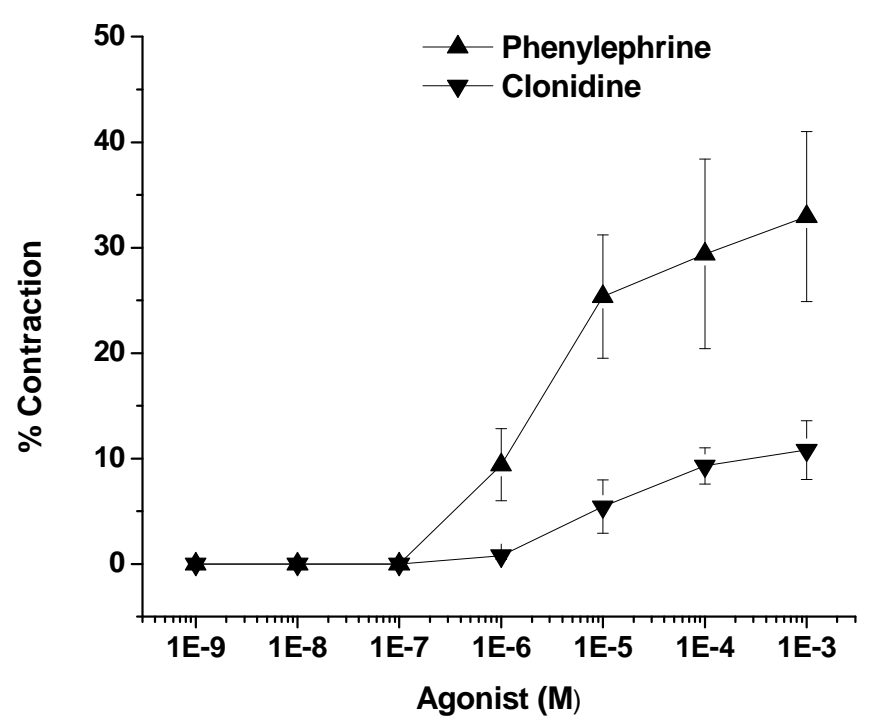

B

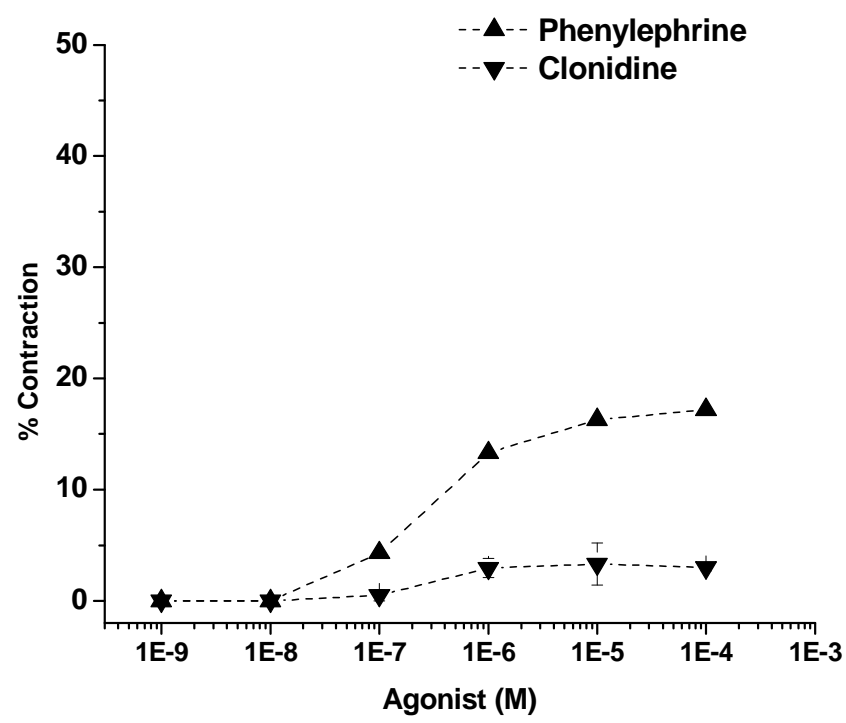

Figure 2: Dose-response curves for phenylephrine and clonidine. A, phenylephrine $(n=2)$ caused substantial contractions of third order mesenteric arteries starting at $10^{-6} \mathrm{M}$ compared to clonidine $(\mathrm{n}=2)$ in rat mesenteric arteries. $\mathrm{B}$, phenylephrine $(\mathrm{n}=1)$ was more a efficacious venoconstrictor compared to clonidine $(n=2)$ in third order mesenteric veins. Data in both figures are mean \pm SEM and $\mathbf{n}$ indicates the number of animals from which the data were obtained.

Given the large number of postjunctional vascular smooth muscle receptors that the sympathetic neurotransmitters can activate, pharmacologic characterization of the receptors using exogenous application of receptor agonists and antagonists will provide an understanding of the sympathetic modulation of mesenteric arteries and veins. In a broader sense, characterization of the receptor population will provide insight into how sympathetic modulators affect the resistance function of mesenteric arteries and the capacitance function of mesenteric veins. Therefore, the objective of this study was to characterize the responses of the postjunctional NE and ATP receptors in healthy rat third order mesenteric arteries and veins.

\section{Materials AND MethodS}

\section{Isolation techniques}

Male Sprague-Dawley rats were maintained according to standards set by the Canadian Council of Animal Care, the Animal Care Committee, and Guelph Animal Care Policy and Procedures 2006. All rats were housed singly and kept in a temperature-controlled room with a 12-hour light-dark cycle. The rats were fed pelleted rat chow and water ad lib.
Twenty-two rats weighing $308.6 \pm 7.0 \mathrm{~g}($ mean \pm SEM) were euthanized with a lethal dose of pentobarbital $(50 \mathrm{mg} / \mathrm{kg})$ given intraperitoneal (IP). Immediately thereafter the mesentery was removed and placed in a cold oxygenated $\left(5 \% \mathrm{CO}_{2}, 95 \% \mathrm{O}_{2}\right.$ ) physiological buffer (Krebs solutions: $117 \mathrm{mM} \mathrm{NaCl}, 4.7 \mathrm{mM} \mathrm{KCl}, 2.5 \mathrm{mM} \mathrm{CaCl}_{2}, 1.2 \mathrm{mM} \mathrm{MgCl}_{2}$, $25 \mathrm{mM} \mathrm{NaHCO} 3,1.2 \mathrm{mM} \mathrm{NaH} \mathrm{PO}_{4}$, and $11 \mathrm{mM}$ Dextrose). The mesentery was pinned flat in a silicone petri dish and the ileum was identified. Third order vessels and associated mesentery were cut out and pinned flat in a small silasticlined recording bath containing cold Krebs solution. The order of the mesenteric vessels were defined by branching based on the superior mesenteric vessels as zero order and the mesenteric vessels adjoining the ileum at their distal end as the fourth order. On average, the outer baseline diameter of the third order arterioles and veins were $248.1 \pm 6.3 \mu \mathrm{m}$ $($ mean \pm SEM) and $242.1 \pm 10.5 \mu \mathrm{m}$ (mean \pm SEM), respectively. With the use of a microscope, the connective tissue and adipose tissue were carefully cut away from the vessels creating a window-like opening around the cleared vessels. The walls of the window were maintained in place by the use of insect pins. In trials in which arteries were studied the associated veins was carefully cut away, and vice-versa. 
A

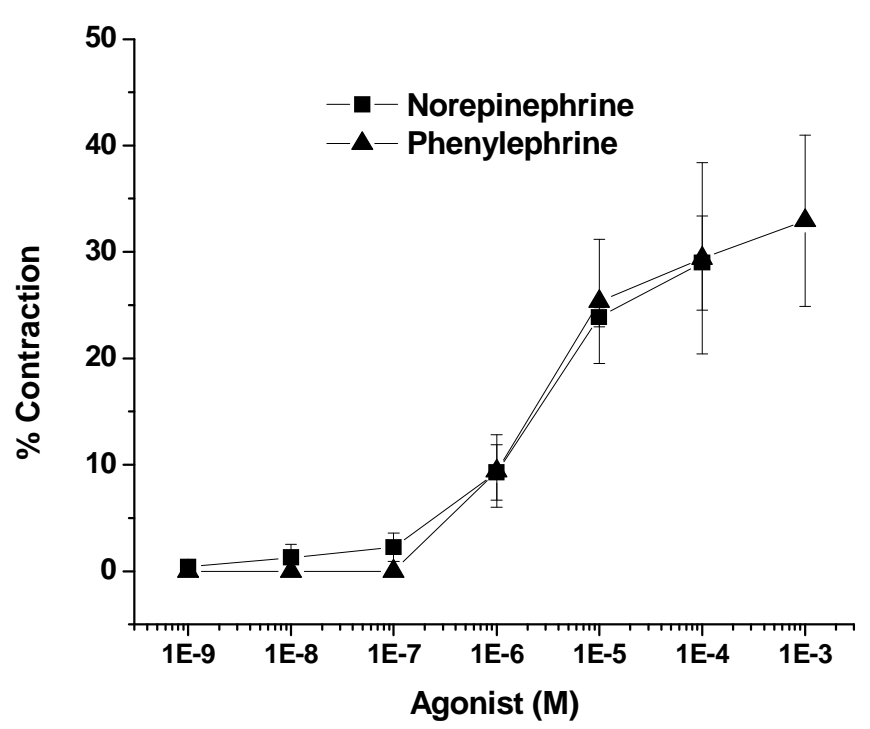

B

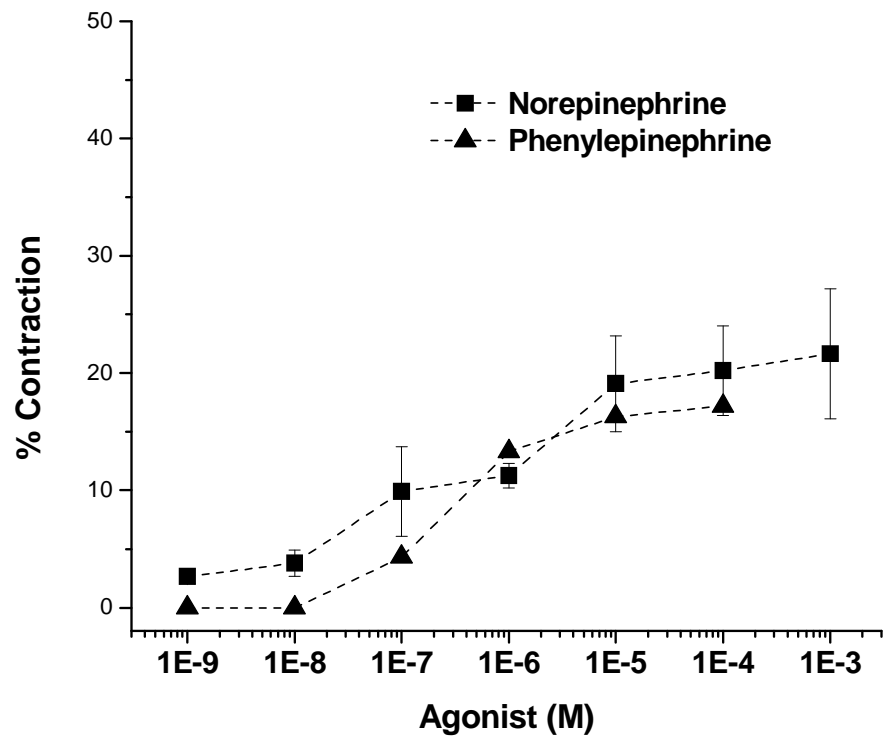

Figure 3: Comparison of dose-response curves for NE- and phenylephrine- induced contractions of rat mesenteric vessels (data replotted from figures 1 and 2). A, both $\mathrm{NE}(\mathrm{n}=3)$ and phenylephrine $(\mathrm{n}=2)$ caused similar effects in third order arteries. $\mathrm{B}$, both $\mathrm{NE}$ $(n=2)$ and phenylephrine $(n=1)$ showed similar trends in contracting third order veins. Data in both figures are mean $\pm S E M$ and $n$ indicates the number of animals from which the data were obtained.

\section{Recording techniques}

After isolation of the mesenteric vein or artery, the recording chamber was placed on an inverted microscope (Olympus CKX41) which contained a black and white video camera (Olympus-100). Real-time images of the vessel were displayed on a computer screen with the assistance of a frame-grabber board. Vessel diameters were determined from images using Diamtrak software, with resolution of changes in vessel diameter of $0.5 \mu \mathrm{m}$ possible. The external diameter of all vessels was determined.

Following isolation and mounting, all vessels were superfused with warm $\left(37.5^{\circ} \mathrm{C}\right)$ oxygenated Krebs solution at rate of $7 \mathrm{~mL} / \mathrm{min}$ for 30 minutes in order to equilibrate vessels before study. A small thermometer was placed in the recording chamber to monitor superfusing solution temperature. In order to be eligible for study, vessels were required to demonstrate adequate contraction following application of $80 \mathrm{mM} \mathrm{KCl}$.

\section{Drug application}

All drugs were added in known concentrations to the superfusing solution. ATP (non-selective purinergic receptor agonist) was added in increasing log doses from $1 \times 10^{-7} \mathrm{M}$ to $3 \mathrm{x} 10^{-3} \mathrm{M}$. In experiments where PPADS (P2X/ P2Y1 receptor antagonist) was used to block the purinergic receptors, PPADS $\left(10^{-5} \mathrm{M}\right)$ was added to the buffer solution and superfused for 20 minutes before the first dose of ATP was added. The non-specific adrenergic agonist NE was added in increasing log doses from $1 \times 10^{-9} \mathrm{M}$ to $1 \times 10^{-3} \mathrm{M}$. In experiments where the selective $\alpha 1$ antagonist prazosin $\left(10^{-7}\right.$ M) was added to the buffer solution, prazosin was superfused for 20 minutes before the $\mathrm{NE}$ doses commenced. In experiments conducted using phenylephrine (selective $\alpha 1$ agonist) and clonidine (selective $\alpha 2$ agonist), the agonists were added in increasing log doses of $1 \times 10^{-9} \mathrm{M}$ to $1 \times 10^{-3} \mathrm{M}$. For every dose administered, the maximum contraction of the vessel was measured and an image of the vessel was saved. All drugs were obtained from Sigma ${ }^{\circledR}$.

\section{Data analysis}

Dose-response curves were plotted as percent contraction of the vessel against a log scale of agonist concentration. Percent contraction was measured as the maximal contraction observed for a dose of agonist reported as a percent change from the resting baseline diameter. All data points are expressed as the mean \pm SEM. Half-maximal effective agonist concentrations $\left(\mathrm{EC}_{50}\right)$ and maximal responses $\left(\mathrm{E}_{\max }\right)$ were calculated from a least-squares fit of 
A

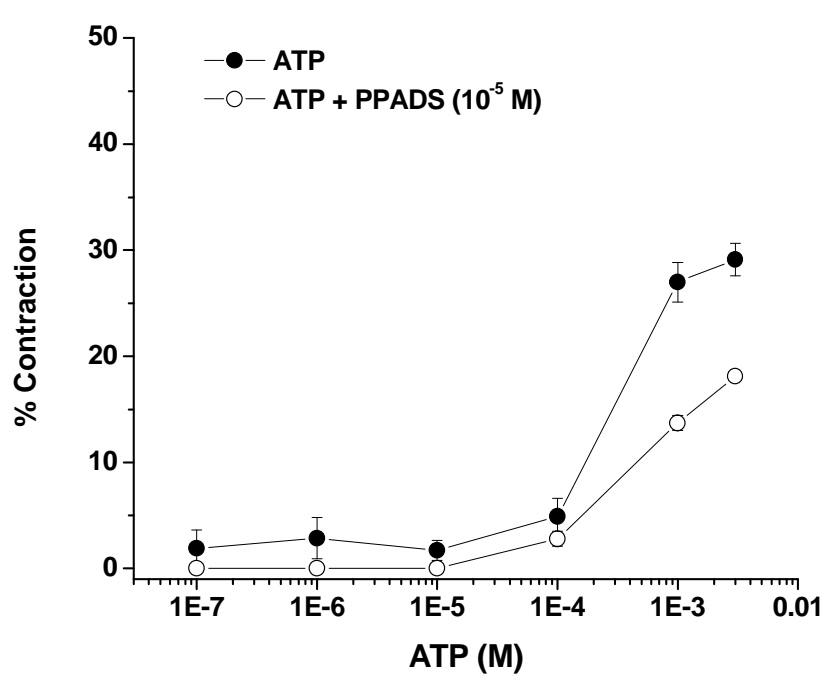

B

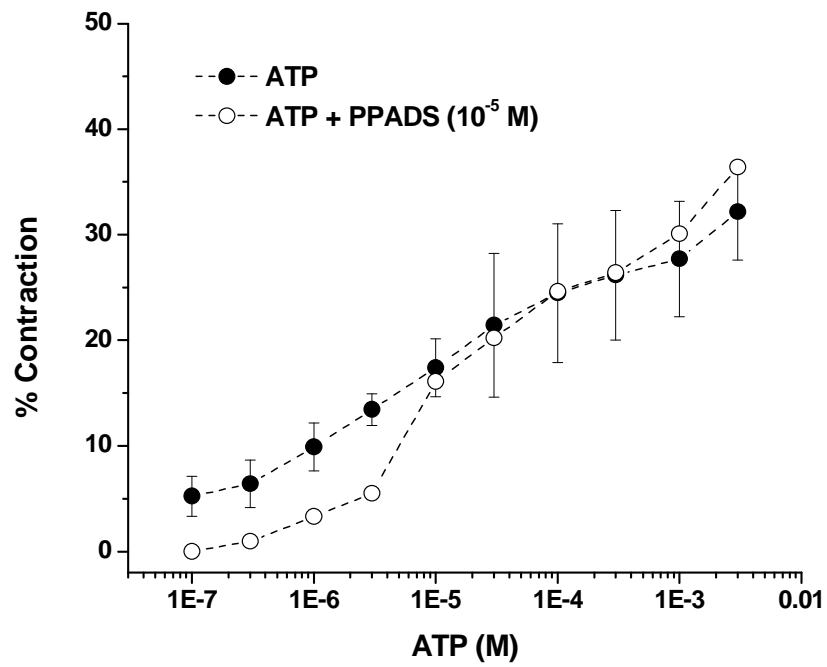

Figure 4: Dose-response curves for ATP in the presence and absence of PPADS $\left(10^{-5} \mathrm{M}\right)$. A, ATP caused contractions of third order mesenteric arteries $(n=8)$. PPADS decreased the ATP-induced contractions $(n=4)$. B, ATP caused contractions of third order mesenteric veins $(n=4)$. PPADS did not have an effect on the ATP-induced contractions ( $n=1)$. Data in both figures are mean \pm SEM and $n$ indicates the number of animals from which the data were obtained.

individual agonist dose-response curves and the average of these values from the curves were calculated. No statistical analyses were conducted due to low $n$ values.

\section{RESULTS}

\section{NE Contracts Mesenteric Arteries and Veins}

The non selective adrenergic receptor agonist (NE) mediated contraction of mesenteric arteries (Figure 1A). Of all drugs studied, NE caused the largest contraction of mesenteric arteries, with an $\mathrm{E}_{\max }$ (maximal contraction) of $31.8 \%$ (Table 1). The selective $\alpha 1$ antagonist prazosin attenuated contractions of mesenteric arteries at low doses of NE but not at higher doses of NE (Figure 1A). Prazosin increased the $\mathrm{NE} \mathrm{EC}_{50}$ (dose of agonist required for $50 \%$ response) in mesenteric arteries (Table 1).

Similarly, NE mediated contractions of mesenteric veins. Trials completed in the presence of prazosin showed a rightward shift in the NE dose-response curve in mesenteric veins (Figure 1B). The $\mathrm{E}_{\max }$ value for the $\mathrm{NE}$ with prazosin dose-response curve was lower than the $\mathrm{E}_{\max }$ value for $\mathrm{NE}$ without prazosin. Additionally, the $\mathrm{NE} \mathrm{EC}_{50}$ was much higher in the presence of prazosin in mesenteric veins (Table 1). Low doses of NE in the presence of prazosin showed no response to exogenous application of $\mathrm{NE}$ in both veins and arteries (Figure 1).

\section{Phenylephrine Causes greater Mesenteric Vessel Contractions than Clonidine}

The dose response curves of the selective $\alpha 1$ agonist phenylephrine and the selective $\alpha 2$ agonist clonidine were compared to assist in the characterization of the adrenergic receptors in mesenteric arteries and veins. Both agonist mediated contractions of mesenteric arteries and veins (Figure 2). The $\mathrm{E}_{\max }$ values for phenylephrine were much greater than that of clonidine in both mesenteric arteries and veins (Table 1) making phenylephrine a more efficacious constrictor agent in these vessels. Extremely high doses of clonidine $\left(10^{-3} \mathrm{M}\right)$ did not mediate venoconstriction, but instead caused dilation (data not shown).

\section{Comparison of NE and Phenylephrine Dose-Response Curves}

Comparison of the NE and phenylephrine dose-response curves also assists in the characterization of the adrenergic receptor expression in mesenteric vessels. In mesenteric arteries, the dose response curves of these agonists was nearly identical (Figure 3A). The $\mathrm{E}_{\max }$ of phenylephrine and $\mathrm{NE}$ were identical at $31.8 \%$, and the $\mathrm{EC}_{50}$ varied only slightly (Table 1). The dose-response curves of NE and phenylephrine in mesenteric veins were also similar (Figure 3B). The $\mathrm{E}_{\max }$ values were similar and the $\mathrm{EC}_{50}$ values were of the same order of magnitude (Table 1). 
Table 2: Comparison of maximal responses $\left(E_{\max }\right)$ and half-maximal effective concentrations $\left(\mathrm{EC}_{50}\right)$ for exogenous applications of purinergic receptor agonists and antagonists in rat mesenteric arteries and veins.

\begin{tabular}{|l|c|c|c|c|}
\hline \multirow{2}{*}{ Drugs } & \multicolumn{2}{|c|}{ Arteries } & \multicolumn{2}{c|}{ Veins } \\
\cline { 2 - 5 } & $\mathbf{E C}_{\mathbf{5 0}}(\mathbf{M})$ & $\mathbf{E}_{\max }(\boldsymbol{\%})$ & $\mathbf{E C}_{\mathbf{5 0}}(\mathbf{M})$ & Emax $(\boldsymbol{\%})$ \\
\hline ATP & $3.3 \times 10^{-4}$ & 31.6 & $9.0 \times 10^{-6}$ & 34 \\
\hline ATP + PPADS & $4.0 \times 10^{-4}$ & 18.0 & $2.0 \times 10^{-5}$ & 38.2 \\
\hline
\end{tabular}

\section{ATP Contracts Mesenteric Arteries and Veins}

Similar to NE, ATP caused dose dependent contraction of both mesenteric arteries and veins (Figure 4). The maximum contraction mediated by ATP in mesenteric arteries was $31.6 \%$ (Table 2). In similar trials completed in the presence of the $\mathrm{P} 2 \mathrm{X}, \mathrm{P} 2 \mathrm{Y}_{1}$ receptor antagonist PPADS, the $\mathrm{E}_{\max }$ due to exogenous application of ATP decreased from $31.6 \%$ to $18.0 \%$ (Table 2). Similarly, ATP mediated contraction of mesenteric veins (Figure 4B). When PPADS was added, there was no shift in the dose-response curve in mesenteric veins. The $\mathrm{E}_{\max }$ and $\mathrm{EC}_{50}$ values for ATP with and without PPADS were similar for third order veins (Table 2).

\section{DISCUSSION}

\section{Interaction of Adrenergic Receptors in Mesenteric Arteries and Veins}

In the present study, the use of the selective $\alpha 1$ antagonist prazosin confirms the prominent role of the $\alpha 1$ adrenergic receptor in NE-derived contractions of mesenteric arteries and veins. Prazosin caused an attenuation of the NE doseresponse curve in mesenteric arteries that was only overcome by very high doses of NE in mesenteric arteries. This observation suggests that prazosin acts as a competitive antagonist of NE. Similarly, prazosin caused a noticeable rightward shift in the NE dose-response curve in mesenteric veins. These findings are supported by a previous study, in which prazosin acted as a simple competitive antagonist of $\mathrm{NE}$ in mouse mesenteric arteries and attenuated NE-derived contractions in mesenteric veins. ${ }^{14}$ Studies completed using neurogenic constrictions of mesenteric vessels also indicate the prominent role of the $\alpha 1$ adrenergic receptor in mesenteric vessels. Prazosin has been shown to abolish or attenuate electrical field stimulation-evoked contractions of guinea pig mesenteric arteries and veins. ${ }^{18}$ In vivo, prazosin has also been shown to completely block NE-derived mesenteric vein constriction and to hyperpolarize venous smooth muscle cells in anesthetized rats. ${ }^{20}$ Indeed, the results of the present study and the above evidence suggest that blockage of the $\alpha 1$ adrenergic receptor causes substantial decreases to vascular smooth muscle tone in both mesenteric arteries and veins.

Further evidence of the prominent role of the $\alpha 1$ adrenergic receptor in mesenteric arteries and veins comes from the use of selective adrenergic receptor agonists in this study. In particular, the selective $\alpha 1$ adrenergic receptor agonist phenylephrine was shown to be a more efficacious constrictor agent than the selective $\alpha 2$ adrenergic receptor agonist clonidine in both mesenteric arteries and veins. Comparison of the phenylephrine and the NE dose-response curves also assists in the characterization of the adrenergic receptors. In the present work, the phenylephrine doseresponse curves generated are very similar to the NE doseresponse curves. This finding is supported by a similar in vitro study also examining the mesenteric arteries and veins of rats. ${ }^{9}$

Though the response was small, the observation in the present study that clonidine mediated direct contractile responses at all is worth noting. While it has been shown that selective $\alpha 1$ receptor activation mediates constriction of mesenteric vessels ${ }^{9}$, this is not the case with selective $\alpha 2$ adrenergic receptor activation. The present study contrasts with previous work that has found that neither clonidine nor UK- 14,304, which are both selective $\alpha 2$ adrenergic agonists, directly constrict mesenteric veins ${ }^{14}$ or arteries ${ }^{9,14}$ when applied exogenously in vitro.

Evidence does exist however that suggests that the $\alpha 2$ adrenergic receptor indirectly contributes to NE induced contraction is mesenteric veins. ${ }^{14}$ UK- 14,304 has been shown to potentiate phenylephrine derived contractions in mesenteric veins in mice. ${ }^{14}$ This finding suggests that activation of the $\alpha 2$ adrenergic receptor sensitizes veins to the constrictor effects of $\alpha 1$ adrenergic receptor activation. It is not currently known how this receptor interaction may occur in the vascular smooth muscle. It may involve a specific signalling cascade such as protein kinase $\mathrm{C}$ (PKC) activation or there may be direct physical interaction between the two receptors. ${ }^{14}$

\section{Purinergic Modulation of Mesenteric Veins}

The most abundant $\mathrm{P} 2$ receptor subtypes known to be present in the peripheral vasculature are several isoforms of the $\mathrm{P} 2 \mathrm{Y}$ receptor as well as the $\mathrm{P}_{2} \mathrm{X}_{1}$ receptor. Reports of other receptor subtypes being expressed in either vascular smooth muscle cells or endothelial cells are present but scarce. ${ }^{19}$ To this end, the present work attempted to characterize contractile responses of ATP in mesenteric arteries and veins using PPADS. PPADS has been shown to antagonize the $\mathrm{P} 2 \mathrm{X}_{1}$ receptor $^{22}$ as well the $\mathrm{P} 2 \mathrm{Y}_{1}$ receptor. ${ }^{15}$

In the present study, ATP was shown to be a potent constrictor of both mesenteric arteries and veins. Pretreatment with PPADS caused a right-ward shift in the ATP dose-response curve in arteries but not veins. This data 
suggests that $\mathrm{P} 2 \mathrm{X}_{1}$ and/or the $\mathrm{P} 2 \mathrm{Y}_{1}$ receptors are expressed prominently in the mesenteric arteries but not veins. In the mesenteric veins, the contractile responses to ATP could have been the result of activation of the $\mathrm{P} 2 \mathrm{Y}_{2}$ and the $\mathrm{P} 2 \mathrm{Y}_{4}$ receptor subtypes in the vascular smooth muscle. Other experiments support the present findings that PPADS cause a concentration dependent inhibition of ATP-induced contractions in rat mesenteric arteries but not veins. ${ }^{5}$ A study of guinea pig mesenteric veins also found that PPADS did not attenuate ATP-derived venoconstriction. ${ }^{11}$ Furthermore, a more recent study also found that neurogenic constrictions could be attenuated by PPADS in mesenteric arteries but not mesenteric veins of rats. ${ }^{13}$

Further evidence of the $\mathrm{P} 2$ receptor expression in mesenteric vessels comes from the use of selective agonists of the $\mathrm{P} 2$ receptors. Though not used in the present study, other experiments have used $\alpha, \beta$-Me-ATP in order to assist in the characterization of $\mathrm{P} 2$ receptors in mesenteric vessels. $\alpha, \beta$-Me-ATP is a potent agonist of the $\mathrm{P}_{2} \mathrm{X}_{1}$ receptor but not of P2Y receptors. ${ }^{4} \mathrm{~A}$ previous study found that $\alpha, \beta-\mathrm{Me}-\mathrm{ATP}$ contracts mesenteric arteries but not veins in rats. ${ }^{5}$ Similarly, immunohistochemical experiments have demonstrated the expression of the $\mathrm{P} 2 \mathrm{X}_{1}$ receptor in the vascular smooth muscle of mesenteric arteries but not veins. ${ }^{5}$ These findings, taken together with the findings of the present study, strongly suggest that $\mathrm{P} 2 \mathrm{X}_{1}$ is selectively expressed in mesenteric arteries and therefore only mediates contractile responses in these vessels and not in mesenteric veins.

\section{Sympathetic Nervous System in the Integrated Environment of the Peripherial Vasculature}

In the present study, agonists and antagonists of adrenergic and purinergic receptors were superfused over isolated mesenteric arteries and veins. This technique, in addition to sympathetic nerve stimulation work, has been used to characterize the vascular smooth muscle receptor population and the contractile responses of those receptors. However, in vivo sympathetic neurogenic influence of net vascular tone is augmented by the intrinsic properties of the vessel, and can also act locally or in humoral influences. The endothelium, for example, releases several vasoactive products that act on the vascular smooth muscle to alter net vascular tone. An important pressor peptide released by endothelial cells is endothelin. ${ }^{17}$ Endothelial cells can also release dilatory substances. These substances which include vasodilatory prostanoids and nitric oxide are released upon activation of adrenergic and purinergic receptors. Endothelial cells are known to express at least five subtypes of adrenoreceptors: $\alpha 2 \mathrm{~A} / \mathrm{D}, \alpha 2 \mathrm{C}, \beta 1, \beta 2$, and $\beta 3 .^{21}$ Furthermore, the purinergic receptors thought to be present in the endothelium are $\mathrm{P} 2 \mathrm{Y}_{1}$, $\mathrm{P}_{2} \mathrm{Y}_{2}$, and $\mathrm{P} 2 \mathrm{Y}_{4}$ receptors. ${ }^{7}$ The superfusion technique used in the present study does not preclude the activation of these receptors and it is likely that the contractile responses to exogenous NE and ATP were attenuated by activation of these endothelial receptors. One observation that indicates this occurred in the present study, in which clonidine at very high concentrations $\left(10^{-3} \mathrm{M}\right)$ mediated a dilation of mesenteric veins. It is possible that the superfusion technique used in this experiment caused endothelial $\alpha 2$ adrenergic receptors to be activated when very high concentrations of clonidine were used.

Though there are many similarities in the data collected between mesenteric arteries and veins, the differences between these vessel types are numerous. The vastly different physiological roles of mesenteric arteries and veins coupled with the complex balance between resistance and capacitance in the splanchnic circulation necessitates a significant differential in the sympathetic neural control of mesenteric arteries and veins. Firstly, it is known that the neurons of the inferior mesenteric ganglion that innervate mesenteric arteries are different than those innervating mesenteric veins. ${ }^{2}$ Beyond the additional differences in physical arrangement of the perivascular nerves ${ }^{13}$, the costorage and release of sympathetic neurotransmitters ${ }^{1}$, as well as the receptor population differs between mesenteric arteries and veins.

In vivo, it is thought that ATP initiates excitatory junctional potentials (EJP) in the vascular smooth muscle of mesenteric arteries through activation of $\mathrm{P} 2 \mathrm{X}$ receptors. This rapid cell depolarization is augmented by $\mathrm{NE}$ acting at adrenergic G-protein receptors which ensure the mobilization of intracellular calcium plus PKC. ${ }^{12}$ In support of this view, the data collected in the present study suggests the importance of both the $\mathrm{P} 2 \mathrm{X}$ and the $\alpha 1$ adrenergic receptor in mesenteric arteries. In contrast, EJP are absent in mesenteric veins $^{6}$, and instead a long-lasting, tonic vascular tone is mediated by $\alpha$ adrenergic receptors ${ }^{14}$ and purinergic P2Y receptors. ${ }^{11}$ The present study presents data that suggests the importance of both specific P2Y subtypes and the $\alpha 1$ adrenergic receptor in mesenteric veins.

Given the prominent role of the splanchnic circulation in the peripheral vasculature in terms of resistance and capacitance, a common application of the present study is to examine how sympathetic modulation of mesenteric arteries and veins differs between healthy and hypertensive rats. For example, a previous study found that NE release from sympathetic nerves associated with mesenteric arteries and veins is increased in DOCA-salt hypertensive rats. ${ }^{9}$ This could theoretically increase blood pressure by increasing resistance in the mesenteric arterioles and by transiently shifting blood from venous to arterial vasculature. Additionally, since sympathetic tone in the venous circulation is elevated in DOCA-salt hypertensive rats ${ }^{3}$ one may expect changes in the contractile responses of ATP and $\mathrm{NE}$ in these animals. However, past studies using similar methods to the present study, have shown that the contractile responses of mesenteric arteries and veins to exogenous $\mathrm{ATP}^{9}$ or $\mathrm{NE}^{14}$ are not altered in DOCA-salt hypertension. Contrasting this view is a recent study in which in situ application of NE to the exposed anesthetized rat mesentery showed increased reactivity in mesenteric veins of DOCAsalt rats. ${ }^{20}$ Further research is necessary in order to determine 
how the sympathetic innervation of the mesenteric vasculature is altered in experimental animal models of hypertension.

\section{Conclusions}

The data presented in this study confirms that NE and ATP contract mesenteric arteries and veins through activation of adrenergic and purinergic vascular smooth muscle receptors respectively. The use of selective adrenoreceptor agonists and antagonists suggests that the $\alpha 1$ adrenergic receptor is the primary adrenoreceptor mediating responses to $\mathrm{NE}$ in these vessels. In addition, the data collected with the use of PPADS suggests that the $\mathrm{P} 2 \mathrm{X}$ and/or the $\mathrm{P} 2 \mathrm{Y}_{1}$ receptors contract mesenteric arteries but do not mediate substantial contractile responses in rat mesenteric veins. Therefore, this data suggests that other purinergic receptors, such as the $\mathrm{P}_{2} \mathrm{Y}_{2}$ and the $\mathrm{P}_{2} \mathrm{Y}_{4}$ receptor subtypes, mediate venoconstriction in these vessels in response to ATP. The present study supports the concept that the sympathetic nervous system is an important modulator of net vascular tone in mesenteric arteries and veins, and that sympathetic modulation of these vessels is an important regulator of the resistance function of mesenteric arteries and the capacitance function of mesenteric veins.

\section{Acknowledgements}

We would like to acknowledge Dr. Saad Enouri and Dave Robinson for their assistance with this project. In addition, we would like to acknowledge Dr. Ron Johnson for his leadership on this project as well NSERC for providing the financial support for this study.

\section{REFERENCES}

1. Bobalova $\mathbf{J}$ and Mutafova-Yambolieva VN. Co-release of endogenous ATP and noradrenaline from guinea-pig mesenteric veins exceeds co-release from mesenteric arteries. Clin.Exp.Pharmacol.Physiol. 28: 5-6: 397-401, 2001.

2. Browning KN, Zheng Z, Kreulen DL and Travagli RA. Two populations of sympathetic neurons project selectively to mesenteric artery or vein. Am.J.Physiol. 276: 4 Pt 2: H1263-72, 1999.

3. Fink GD, Johnson RJ and Galligan JJ. Mechanisms of increased venous smooth muscle tone in desoxycorticosterone acetate-salt hypertension. Hypertension 35: 1 Pt 2: 464-469, 2000.

4. Fredholm BB, Abbracchio MP, Burnstock G, Dubyak GR, Harden TK, Jacobson KA, Schwabe U and Williams M. Towards a revised nomenclature for P1 and P2 receptors. Trends Pharmacol.Sci. 18: 3: 79-82, 1997.

5. Galligan JJ, Hess MC, Miller SB and Fink GD. Differential localization of $\mathrm{P} 2$ receptor subtypes in mesenteric arteries and veins of normotensive and hypertensive rats. J.Pharmacol.Exp.Ther. 296: 2: 478485, 2001.

6. Kreulen DL. Properties of the venous and arterial innervation in the mesentery. J.Smooth Muscle Res. 39: 6: 269-279, 2003.

7. Kunapuli SP and Daniel JL. P2 receptor subtypes in the cardiovascular system. Biochem.J. 336 ( Pt 3): Pt 3: 513 523, 1998.

8. Lee CH, Poburko D, Sahota P, Sandhu J, Ruehlmann DO and van Breemen C. The mechanism of phenylephrine-mediated $\quad[\mathrm{Ca}(2+)](\mathrm{i}) \quad$ oscillations underlying tonic contraction in the rabbit inferior vena cava. J.Physiol. 534: Pt 3: 641-650, 2001.

9. Luo M, Hess MC, Fink GD, Olson LK, Rogers J, Kreulen DL, Dai $X$ and Galligan JJ. Differential alterations in sympathetic neurotransmission in mesenteric arteries and veins in DOCA-salt hypertensive rats. Auton.Neurosci. 104: 1: 47-57, 2003.

10. Morhrman DE and Heller LJ. Cardiovascular Physiology. New York: Lange Medical Books, 2006, p. 138-139.

11. Mutafova-Yambolieva VN, Carolan BM, Harden TK and Keef KD. Multiple P2Y receptors mediate contraction in guinea pig mesenteric vein. Gen.Pharmacol. 34: 2: 127-136, 2000.

12. Pablo Huidobro-Toro $\mathbf{J}$ and Veronica Donoso $\mathbf{M}$. Sympathetic co-transmission: the coordinated action of ATP and noradrenaline and their modulation by neuropeptide $\mathrm{Y}$ in human vascular neuroeffector junctions. Eur.J.Pharmacol. 500: 1-3: 27-35, 2004.

13. Park J, Galligan JJ, Fink GD and Swain GM. Differences in sympathetic neuroeffector transmission to rat mesenteric arteries and veins as probed by in vitro continuous amperometry and video imaging. J.Physiol. 584: Pt 3: 819-834, 2007.

14. Perez-Rivera AA, Hlavacova A, Rosario-Colon LA, Fink GD and Galligan JJ. Differential contributions of alpha- 1 and alpha- 2 adrenoceptors to vasoconstriction in mesenteric arteries and veins of normal and hypertensive mice. Vascul Pharmacol. 46: 5: 373-382, 2007.

15. Ralevic V and Burnstock G. Discrimination by PPADS between endothelial P2Y- and P2U-purinoceptors in the rat isolated mesenteric arterial bed. Br.J.Pharmacol. 118: 2: 428-434, 1996.

16. Ross $\mathrm{MH}$ and Pawlina WP. Histology: A text and Atlas. Baltimore, MD: Lippincott Williams \& Wilkins, 2006, p. 906-371.

17. Schiffrin EL. Vascular endothelin in hypertension. Vascul Pharmacol. 43: 1: 19-29, 2005.

18. Smyth L, Bobalova J, Ward SM, Keef KD and Mutafova-Yambolieva VN. Cotransmission from sympathetic vasoconstrictor neurons: differences in guinea-pig mesenteric artery and vein. Auton.Neurosci. 86: $1-2$ : $\quad 18-29, \quad 2000$. 
19. Wang L, Karlsson L, Moses S, Hultgardh-Nilsson A, Andersson M, Borna C, Gudbjartsson T, Jern S and Erlinge D. P2 receptor expression profiles in human vascular smooth muscle and endothelial cells. J.Cardiovasc.Pharmacol. 40: 6: 841-853, 2002.

20. Xu H, Fink GD and Galligan JJ. Increased sympathetic venoconstriction and reactivity to norepinephrine in mesenteric veins in anesthetized DOCA-salt hypertensive rats. Am.J.Physiol.Heart Circ.Physiol. 293: 1: H160-8, 2007.

21. Zang WJ, Zacharia J, Lamont $\mathrm{C}$ and Wier WG. Sympathetically evoked $\mathrm{Ca} 2+$ signaling in arterial smooth muscle. Acta Pharmacol.Sin. 27: 12: 1515-1525, 2006.

22. Ziganshin AU, Hoyle $\mathrm{CH}$, Lambrecht G, Mutschler E, Bumert HG and Burnstock G. Selective antagonism by PPADS at P2X-purinoceptors in rabbit isolated blood vessels. Br.J.Pharmacol. 111: 3: 923-929, 1994. 